17. Баум В.В., Чистохвалов В.Н., Филиппов В.М. Система зачетных единиц (кредитов) как один из инструментов признания квалификаций. М.: РУДН, 2008. $166 \mathrm{c}$.

18. Баранова Л.Л. Онтология английской письменной речи. Орфоэпия и орфография современного английского языка. М.: ПСТГУ, 2008. 312 с.

19. Колоницкая О.Л., Хруненкова М.Л. Обучение студентов иноязычной письменной речи [Электронный ресурс] // Интернет-журнал «Эйдос». 2010. 19 марта. - http://eidos.ru/journal/2010/0319-8.htm.

20. Сон И.С. Особенности оценивания знаний по иностранному языку (говорение, письмо) по балльно-рейтинговой системе // Теория и практика образования в современном мире: мат-лы II междунар. науч. конф. (г. Санкт-Петербург, ноябрь 2012 г.). СПб.: Реноме, 2012. С. 185-188.

21. Макарова Ю.А. Оценивание иноязычных креативных текстов студентов как методическая проблема // Профессиональное образование в России и за рубежом. 2016. № 4 (24). С. 196-203.

22. Пивоварова С.Н. Система оценивания результатов учебной деятельности учащихся школы // Муниципальное образование: инновации и эксперимент 2011. № 4. C. 20-25.

23. Pond K., Coates D., Palermo O.A. Student experiences of peer review marking of team projects // International journal of management education. 2007. № 6 (2). P. $30-43$.

\title{
ADVANTAGES OF AUTHENTIC ASSESSMENT OVER TRADITIONAL ASSESSMENT WHILE TEACHING ENGLISH TO UNIVERSITY STUDENTS MAJORING IN NON-LINGUISTIC SUBJECTS
}

(C) 2018
Abramova Irina Evgenyevna, doctor of philological sciences, associate professor, head of Foreign Languages for Students of Humanities Department
Shishmolina Elena Petrovna, candidate of pedagogical sciences, associate professor of Foreign Languages for Students of Humanities Department

Ananyina Anastasia Valeryevna, senior lecturer of Foreign Languages for Students of Humanities Department Petrozavodsk State University (Petrozavodsk, Russian Federation)

Abstract. The paper analyzes existing approaches to assessing the results of teaching foreign languages to the university students majoring in non-linguistic subjects with a special focus on the advantages of authentic assessment. The authors stress the state-level need to develop and implement effective assessment tools for ESL university teaching, and substantiate the effectiveness of authentic assessment for increasing students' motivation to learn English. They identify advantages of authentic assessment, including a possibility to track individual students' learning progress, to effectively use peer assessment and self-assessment, to focus on students' performance indicators, to create a success effect, and to present actual teaching and learning results or personal development achievements in the form of presentations, projects and other tangible accomplishments. The paper describes a unified system of control, assessment and evaluation of ESL teaching and learning results, developed by Foreign Languages for Students of Humanities Department at Petrozavodsk State University (Russia) for modeling a foreign-language environment and enhancing students' language socialization. The authors give a detailed account of establishing procedures for the assessment of speaking and writing skills, and analyze a didactic potential of a foreign language portfolio as one of authentic assessment tools. They come to the conclusion that peer assessment, self-assessment and other authentic assessment methods help to shift the focus from teaching to learning and create optimal conditions for studentcentered education process.

Keywords: authentic assessment; university students majoring in non-linguistic subjects; self-assessment; peer assessment; foreign language portfolio; speaking skills assessment; writing skills assessment; quality assessment; foreign language learning motivation; assessment recommendations.

\section{ТИПЫ И ВИДЫ УЧЕБНО-ПРОФЕССИОНАЛЬНЫХ ЗАДАЧ В ФУНДАМЕНТАЛЬНОЙ ПОДГОТОВКЕ ВРАЧЕЙ}

Астанина Светлана Юрьевна, кандидат педагогических наук, профессор кафедры медицинской педагогики, философии и иностранных языков, начальник управления научно-методической и образовательной деятельности Российская медицинская академия непрерывного профессионального образования (г. Москва, Российская Федераџия)

Аннотация. В статье рассматривается проблема фундаментальной подготовки врачей на основе решения разных групп учебно-профессиональных задач в непрерывном медицинском образовании. Анализ взглядов различных ученых позволил определить, что непрерывность и целостность образования обеспечивается преемственностью в решении учебно-профессиональных задач, образованных от профессиональных задач. В связи с тем, что в здравоохранении наблюдается достаточно быстрое внедрение результатов достижений фундаментальных наук (молекулярной биологии, биофизики, биохимии) в процессы оказания медицинской 

помощи, повышается наукоемкость трудовых функций, увеличивается их многообразие, что приводит к увеличению профессиональных задач. Взаимосвязь типов и классов учебно-профессиональных задач обеспечивает преемственность содержания фундаментальной подготовки врачей. Между группами учебно-профессиональных задач (инвариантные и вариативные) образуются внутрипредметные связи, обеспечивающие целостность содержания биологической подготовки врачей. Классификация учебно-профессиональных задач на типы, классы и виды позволяет систематизировать содержание фундаментальной подготовки врачей в соответствии с актуальными образовательными потребностями обучающихся врачей и запросами практического здравоохранения, что, в свою очередь, обеспечивает преемственность, выражающуюся в последовательности и согласованности содержания, форм и методов учебного процесса, в последовательности и согласованности обучения на различных этапах медицинского образования.

Ключевые слова: фундаментальная подготовка врачей; дополнительное профессиональное образование; непрерывность медицинского образования; преемственность профессионального образования; медикобиологическая подготовка; профессиональные задачи; учебно-профессиональные задачи; типы и виды учебно-профессиональных задач.

\section{Введение}

В современный период обеспечение развития профессионального образования является важной проблемой. В основу профессиональной подготовки и совершенствования специалистов положен принцип непрерывности, подразумевающий последовательный и регулярный процесс совершенствования профессиональных компетенций [1;2].

Актуальность непрерывного образования декларирована федеральным законом: «Система образования создает условия для непрерывного образования посредством реализации основных образовательных программ и различных дополнительных образовательных программ, предоставления возможности одновременного освоения нескольких образовательных программ, а также учета имеющихся образования, квалификации, опыта практической деятельности при получении образования» [2].

Концепция непрерывного медицинского образования предполагает, что развитие подготовки врачей обеспечивается формированием компетенций, которые у врача формируются, совершенствуются на всех уровнях медицинского образования.

В русле концепции непрерывного образования интересны взгляды на непрерывность многих ученых.

Например, А.А. Леонтьев связывает преемственность с непрерывностью и целостностью образования, в рамках которого должны последовательно и постоянно решаться учебные задачи: «...наличие последовательной цепи учебных задач на всем протяжении образования, переходящих друг в друга и обеспечивающих постоянное, объективное и субъективное продвижение учащихся вперед на каждом из последовательных временных отрезков» [3].

В.А. Дегтярев, О.А. Хилькевич обращают внимание на то, что «непрерывность и преемственность можно рассматривать как базовые идеи/основания в моделировании системы оценки качества образования, в том числе и на ступени высшего профессионального образования» [4; 5].

С точки зрения В.Н. Просвиркина, «... преемственность представляет собой процесс поступательного развития человека на каждой ступени системы непрерывного образования, основанного на связи этапов обучения и развития, осуществляемого при опоре и учете новообразований предшествующих этапов в последующих и построения системы условий, способствующих комфортному переходу учащихся с одной ступени образовательного процес- са на последующую, позволяющих всесторонне развивать личность с учетом индивидуальных особенностей субъектов образовательной деятельности» [6].

В непрерывном образовании устанавливается новый тип образовательных результатов, не сводимый к комбинации знаний и навыков, а ориентированный на способность и готовность личности к решению разного рода задач, проблем, готовность к продуктивной деятельности. Иными словами, в образовании и в практическом здравоохранении происходит перенос акцента на результат (что обучающийся будет в состоянии делать) [7].

В.И. Байденко: «Компетенции/компетентности интерпретируются как единый (согласованный) язык для описания академических и профессиональных профилей и уровней высшего образования. Иногда говорят, что язык компетенций является наиболее адекватным для описания результатов образования» [8-10].

В работах А.П. Тряпицыной «...компетентность это способность решать профессиональные проблемы и задачи, возникающие в реальных ситуациях профессиональной деятельности» [11].

Составляющими компетенций являются не только профессиональные знания и умения, характеризующие квалификацию, но и способность к работе в группе, умение использовать информацию [12].

А.А. Вербицкий обращает внимание на такую проблему: «Как приблизить обучение в вузе к этим реалиям, интегрировать образование, науку и практику, не утратив мощности теоретического знания? Это предполагает не отказ от изложения теории и не лозунг «назад к практике», а психологически, педагогически и методически обоснованное модельное ее «замещение», воссоздание в образовании предметного и социального контекстов усваиваемой студентами профессиональной деятельности» [13].

Профессиональная задача представляет собой систему смоделированных разноуровневых заданий по организации практической деятельности. С их помощью осуществляется перенос теоретических знаний, направленных на подготовку к профессиональной деятельности, в реальные условия [14].

Содержание медицинского образования основано на требованиях, предъявляемых обществом к содержанию медицинской помощи и квалификации медицинских работников, и ориентировано на подготовку компетентных, ответственных специалистов, которые должны обладать не только специальными медицинскими знаниями, но и психолого-педагогическими компетенциями [15]. 
В подготовке медицинских специалистов способность и готовность врача решать реальные профессиональные задачи приобретает первостепенное значение.

Цель исследования: определение типов и видов учебно-профессиональных задач в фундаментальной подготовке врачей, обеспечивающих отбор содержания и организацию учебного процесса в соответствии с актуальными образовательными потребностями обучающихся врачей и запросами практического здравоохранения.

\section{Результаты исследований и их обсуждение}

В связи с тем, что в здравоохранении наблюдается достаточно быстрое внедрение результатов достижений фундаментальных наук (молекулярной биологии, биофизики, биохимии) в процессы оказания медицинской помощи, повышается наукоемкость трудовых функций врачей, увеличивается их многообразие.

С целью поддержания качества оказания медицинской помощи возрастают требования к квалификации врачей, что находит отражение в профессиональных стандартах как многофункциональном нормативном документе, предназначенном для:

- оценки уровня квалификации работников, а также выпускников учреждений профессионального образования;

- разработки образовательных стандартов и образовательных программ [16].

Таким образом, между профессиональными и образовательными стандартами устанавливается взаимосвязь: профессиональные стандарты определяют требования к врачу в выполнении трудовых функций, а образовательные стандарты предъявляют требования к образовательному процессу по подготовке врача к выполнению им трудовых функций. Оценить результат подготовки врача возможно только на основе сформированных компетенций.

В реальной профессиональной деятельности трудовые функции (в диагностической, лечебной, профилактической, реабилитационной деятельности) часто интегрируются между собой в целях решения конкретной профессиональной задачи. Взаимосвязь этих функций осуществляется на основе решения проблем, связанных с конкретным пациентом, что определяет содержание конкретной профессиональной задачи. Однако прямой перенос профессиональной задачи в условия образовательного процесса невозможен по причине многофакторности профессиональной задачи.

Под «профессиональной задачей» понимается проблемная ситуация в реальной профессиональной деятельности. Решение этой проблемной ситуации означает решение профессиональной задачи [17].

Подготовка врача к решению профессиональной задачи возможна путем последовательного решения учебно-профессиональных задач. А.П. Тряпицына [11] подчеркивает зависимость учебно-профессиональных задач от профессиональных. При этом обращает внимание на то, что учебно-профессиональные задачи формулируются как практические, а не академические задачи [11, с. 18$]$.
Таким образом, взаимосвязь профессиональных и образовательных стандартов осуществляется через взаимосвязь профессиональных и учебно-профессиональных задач. Решение учебно-профессиональных задач приводит к способности и готовности врачей решать профессиональные задачи (рисунок 1).

Анализ профессиональной деятельности врачей позволил вычленить профессиональные задачи в зависимости от вида профессиональной деятельности (ФГОС ВО):

1) в профилактической деятельности:

- предупреждение возникновения заболеваний среди населения путем проведения профилактических и противоэпидемических мероприятий;

- проведение профилактических медицинских осмотров, диспансеризации, диспансерного наблюдения;

- проведение сбора и медико-статистического анализа информации о показателях здоровья населения различных возрастно-половых групп, характеризующих состояние их здоровья;

2) в диагностической деятельности:

- диагностика заболеваний пациентов с использованием лабораторных, инструментальных и иных методов исследования;

- диагностика неотложных состояний;

3) в лечебной деятельности:

- оказание специализированной медицинской помощи;

- участие в оказании скорой медицинской помощи при состояниях, требующих срочного медицинского вмешательства;

- оказание медицинской помощи при чрезвычайных ситуациях, в том числе участие в медицинской эвакуации;

4) в реабилитационной деятельности:

- проведение медицинской реабилитации и санаторно-курортного лечения;

5) в психолого-педагогической деятельности:

- формирование у населения, пациентов и членов их семей мотивации, направленной на сохранение и укрепление своего здоровья и здоровья окружающих.

В свою очередь, выявленные профессиональные задачи позволили определить содержания учебнопрофессиональных задач, являющихся структурной единицей содержания фундаментальной подготовки врачей. Рассмотрим зависимость содержания учебнопрофессиональных задач от профессиональных задач в аспекте медико-биологической подготовки на примере трудовой функции врача в профилактической деятельности [18] (таблица 1).

Подготовка медицинских специалистов - процесс многоэтапный и непрерывный, основывающейся на дидактическом принципе преемственности.

Ю.Н. Кулюткин, Г.С. Сухобская, Я.И. Петров, рассматривая принципы построения образовательного процесса, обращают внимание на необходимость использования принципа преемственности в организации непрерывного образования: «Принцип преемственности является необходимым условием достижения непрерывности, поступательности и интегративности образования» [19, с. 203]. 


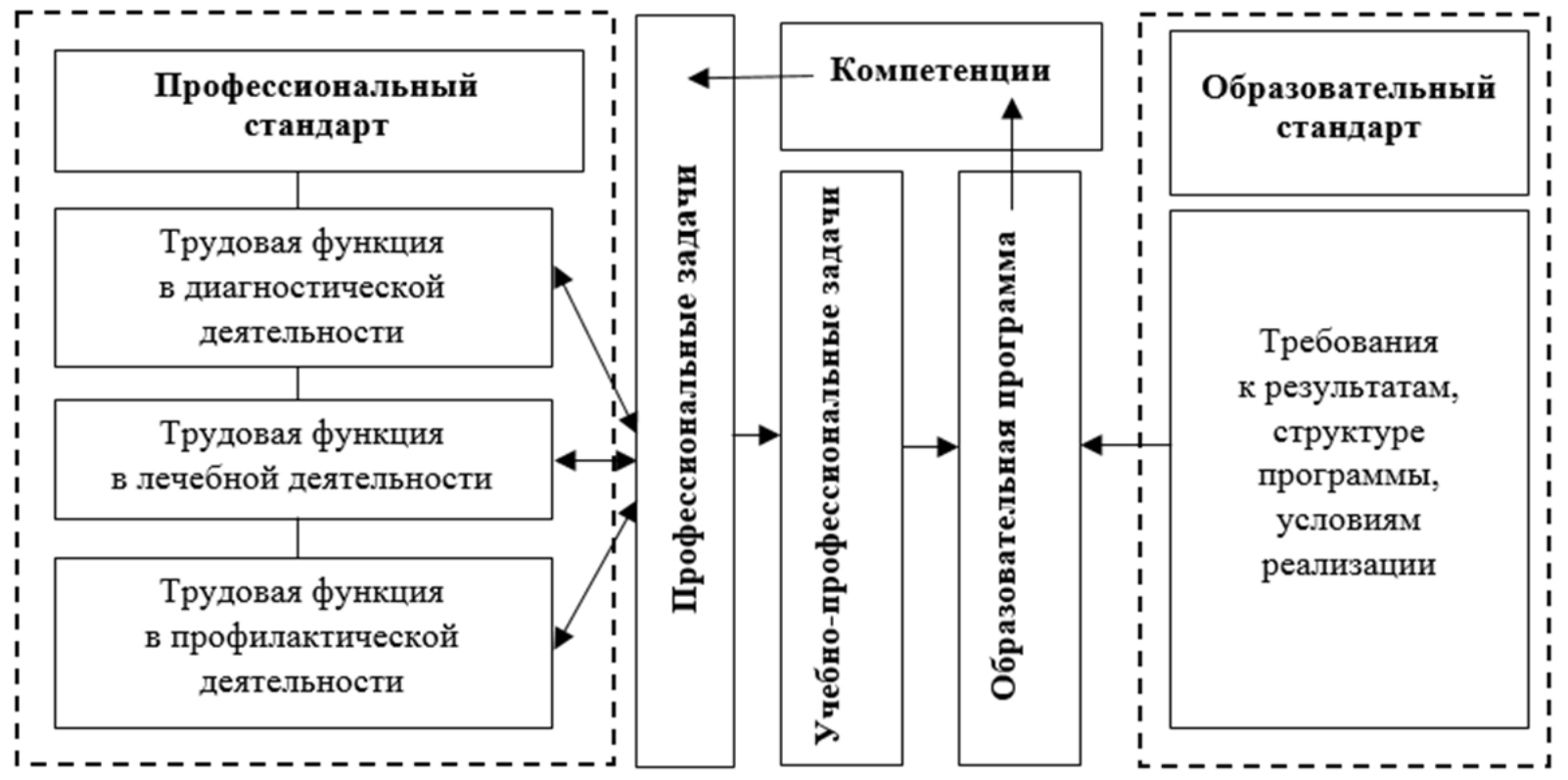

Рисунок 1 - Взаимосвязь профессиональных и образовательных стандартов

Таблица 1 - Содержание профессиональных, учебно-профессиональных задач врачей (на примере профилактической деятельности)

\begin{tabular}{|c|c|c|}
\hline $\begin{array}{l}\text { Вид } \\
\text { ПД }\end{array}$ & Профессиональные задачи врачей & $\begin{array}{c}\text { Учебно-профессиональные задачи } \\
\text { фундаментальной подготовки врачей }\end{array}$ \\
\hline \multirow{3}{*}{ 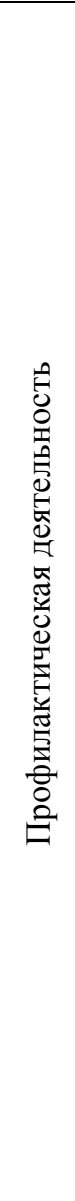 } & $\begin{array}{l}\text { предупреждение возникновения за- } \\
\text { болеваний среди населения путем } \\
\text { проведения профилактических и } \\
\text { противоэпидемических мероприя- } \\
\text { тий }\end{array}$ & $\begin{array}{l}\text { выявление факторов окружающей среды, способствующих воз- } \\
\text { никновению заболеваний; } \\
\text { определение суммарного влияния факторов на состояние здоро- } \\
\text { вья человека; } \\
\text { оценивание негативной роли средовых факторов на организм; } \\
\text { обоснование приспособительных механизмов организма к факто- } \\
\text { рам среды; необходимости рационального природопользования } \\
\text { в сохранении здоровья населения; } \\
\text { прогнозирование возникновения эпидемических ситуаций }\end{array}$ \\
\hline & $\begin{array}{l}\text { проведение профилактических ме- } \\
\text { дицинских осмотров, диспансериза- } \\
\text { ции, диспансерного наблюдения }\end{array}$ & $\begin{array}{l}\text { объяснение принципов здорового образа жизни с позиции биоло- } \\
\text { гических и экологических закономерностей; роли паразитизма в } \\
\text { природе и эволюции; значения патогенных грибов в природе и } \\
\text { эволюции; } \\
\text { выяяление и обоснование причинно-следственных связей между } \\
\text { охраной окружающей среды и здоровьем человека; экологически } \\
\text { обусловленных заболеваний и патологических состояний; меха- } \\
\text { низмов бактериального, паразитического, вирусного заражения } \\
\text { организма; механизмов влияния факторов химической и физиче- } \\
\text { ской природы; } \\
\text { характеристика медико-генетического консультирования, гене- } \\
\text { тического скрининга и обоснование значимости и необходимости } \\
\text { медико-генетического консультирования }\end{array}$ \\
\hline & $\begin{array}{l}\text { проведение сбора и медико- } \\
\text { статистического анализа информа- } \\
\text { ции о показателях здоровья населе- } \\
\text { ния различных возрастно-половых } \\
\text { групп, характеризующих состояние } \\
\text { их здоровья }\end{array}$ & $\begin{array}{l}\text { анализ состояния здоровья населения с позиции влияния факто- } \\
\text { ров среды, популяционной генетики, биологических и экологи- } \\
\text { ческих законов; } \\
\text { объяснение приспособительных механизмов популяции населе- } \\
\text { ния; } \\
\text { прогнозирование состояния здоровья различных возрастно- } \\
\text { половых групп в зависимости от окружающей среды и гетеро- } \\
\text { генного состава популяции }\end{array}$ \\
\hline
\end{tabular}

Подготовка врачей к решению разного типа и уровня профессиональных задач осуществляется в направлении: от овладения студентом медицинского вуза (уровень специалитета) совокупностью общебиологических знаний, умений, навыков, содействующих формированию общепрофессиональных ком- петенций, к готовности врачей различных медицинских специальностей (уровень подготовки кадров высшей квалификации в ординатуре) к оказанию специализированной помощи и далее (повышение квалификации врачей в дополнительном профессиональном образовании) - к углублению медико-био- 
логической подготовки врача, направленной на совершенствование/или формирование новых профессиональных компетенций, обеспечивающих оказание специиализированной, узкоспециализированной и высокотехнологичной медицинской помощи в связи с расширением спектра трудовых функиий, связанных с увеличением функциональных обязанностей врачей различных медицинских специальностей [20].

Анализ трудовых функций врачей позволил определить содержание профессиональных задач, которые, в свою очередь, определили типы учебнопрофессиональных задач (таблица 2).

Таблица 2 - Типы учебно-профессиональных задач

\begin{tabular}{|c|c|l|}
\hline $\begin{array}{c}\text { Тип учеб- } \\
\text { но-про- } \\
\text { фессио- } \\
\text { нальной } \\
\text { задачи }\end{array}$ & $\begin{array}{c}\text { Профес- } \\
\text { сиональ- } \\
\text { ные зада- } \\
\text { чи }\end{array}$ & $\begin{array}{c}\text { Содержание учебно- } \\
\text { профессиональной задачи }\end{array}$ \\
\hline $\begin{array}{l}\text { инвари- } \\
\text { антные }\end{array}$ & $\begin{array}{l}\text { обще- } \\
\text { профес- } \\
\text { сиональ- } \\
\text { ные }\end{array}$ & $\begin{array}{l}\text { задачи, содержание кото- } \\
\text { рых не зависит от направ- } \\
\text { ления подготовки врача }\end{array}$ \\
\hline вариатив- & $\begin{array}{l}\text { направ- } \\
\text { лениям } \\
\text { поде }\end{array}$ & $\begin{array}{l}\text { задачи, содержание кото- } \\
\text { рых образовано от про- } \\
\text { фессиональных задач, свя- } \\
\text { занных с трудовыми } \\
\text { функциями по направле- } \\
\text { ниям подготовки врача: } \\
\text { а) клинической медицины; } \\
\text { б) медико-профилакти- } \\
\text { ческой медицины }\end{array}$ \\
\hline
\end{tabular}

Так, в высшем образовании учебно-профессиональные задачи инвариантного типа обеспечивают преемственность между разными этапами подготовки врачей (уровень специалитета). Содержание инвариантных задач является основой для вариативных задач. Учебно-профессиональные задачи вариативного типа обеспечивают преемственность в подготовке врачей различных направлений (клинической и профилактической медицины).

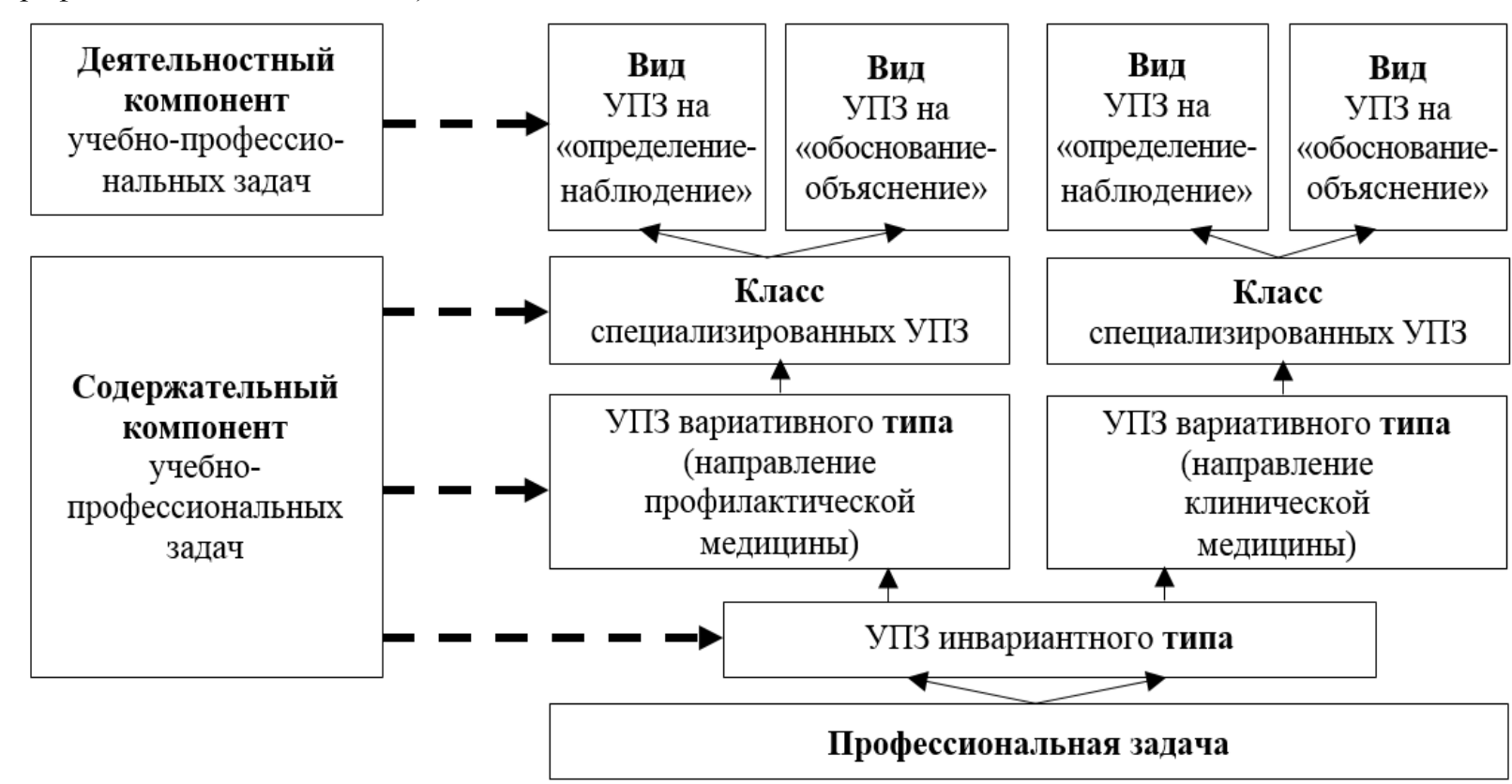

Рисунок 2 - Взаимосвязь типов, классов и видов учебно-профессиональных задач
Подготовка врачей к оказанию специализированной медицинской помощи требует от врача способности и готовности к решению профессиональных задач, связанных с выполнением трудовых функций врачей-специалистов (например, врач-неонатолог, врач-офтальмолог и др.). На этом этапе многообразие трудовых функций, интеграция этих функций способствует многообразию профессиональных задач. Их содержание определяется трудовыми функциями, связанными с оказанием специализированной медицинской помощи. Учебно-профессиональные задачи, образованные от «специализированных» профессиональных задач, обеспечивают преемственность между подготовкой врачей в ординатуре и подготовкой врачей в дополнительном профессиональном образовании, между выполнением трудовых функций, связанных с оказанием специализированной и высокотехнологичной медицинской помощью. Содержание различных групп учебно-профессиональных задач зависит от содержания профессиональных задач.

Решение учебно-профессиональной задачи в каждой группе осуществляется с использованием таких видов учебной деятельности, как обоснование, объяснение особенностей биологических факторов, вызывающих патологические состояния, болезни, объяснение влияния факторов среды на жизнедеятельность человека, что предполагает доминирование в учебном процессе теоретического этапа обучения и обеспечивают отбор соответствующих методов теоретического обучения.

Учебно-профессиональные задачи, требующие определение биологических объектов при лабораторных, цитологических, гистологических, экологических исследованиях, наблюдение за динамикой биологических процессов на разных подуровнях организации организма человека (например, влияние канцерогенов на метаболизм клеток соединительной ткани), предполагают увеличение объема практической подготовки врача и позволяют определить наиболее эффективные методы практического обучения (рисунок 2). 


\section{Выводы}

Содержание учебно-профессиональных задач определяется содержанием профессиональных задач. Между группами учебно-профессиональных задач образуются внутрипредметные связи, обеспечивающие целостность содержания биологической подготовки врачей. Взаимосвязь типов и классов учебно-профессиональных задач обеспечивает преемственность содержания фундаментальной подготовки врачей.

В зависимости от преобладающего вида деятельности в решении профессиональной задачи различают: учебно-профессиональные задачи на «обоснование-объяснение» и учебно-профессиональные задачи на «определение-наблюдение», что определяет деятельностный компонент учебно-профессиональных задач. В свою очередь, деятельностный компонент учебно-профессиональных задач определяет практическую направленность задачи, максимально приближая учебный процесс к реальным профессиональным условиям и выполняемым трудовым функциям.

Классификация учебно-профессиональных задач на типы, классы и виды позволяет обеспечивать отбор и систематизацию содержания фундаментальной подготовки врачей в соответствии с актуальными образовательными потребностями обучающихся врачей и запросами практического здравоохранения, что, в свою очередь, обеспечивает преемственность, выражающуюся в последовательности и согласованности содержания, форм и методов учебного процесса; в последовательности и согласованности обучения на различных этапах непрерывного медицинского образования.

\section{Список литературы:}

1. Кувшинов Ю.Я. Непрерывное профессиональное образование как гарантия мастерства специалиста // АВОК: Вентиляция, отопление, кондиционирование воздуха, теплоснабжение и строительная теплофизика. 2006. № 3.

2. Федеральный закон от 29 декабря 2012 г. № 273-Ф3 «Об образовании в Российской Федерации» // Российская газета - Федеральный выпуск. № 5976 (303). 31.12.2012.

3. Леонтьев А.А. Психолого-дидактические основы школьных учебников нового поколения (на примере русского языка и литературы) // «Школа 2100» как образовательная система: сб. мат-лов. Вып. 8. М.: Баласс, Изд. дом РАО, 2005. С. 17-27.

4. Дегтярев В.А. К вопросу о системе непрерывного профессионального образования // Успехи современного естествознания. 2014. № 9, ч. 2. С. 175180.

5. Милькевич О.А. Непрерывность и преемственность как основания моделирования системы оценки качества в условиях модернизации высшего профессионального образования // Личность, семья и общество: вопросы педагогики и психологии: сб. ст. по матер. XVI междунар. науч.-практ. конф. Ч. I. Новосибирск: СибАК, 2012. С. 53-56.

6. Просвиркин В.Н. Технология преемственности в системе непрерывного образования: автореф. дис. ... д-ра пед. наук: 13.00.01. М., 2009. 39 с.
7. Блинов В.И., Виненко В.Г., Сергеев И.С. Методика преподавания в высшей школе: учеб.-практическое пособие. М.: Юрайт, 2014. 315 с.

8. Байденко В.И. Выявление состава компетенций выпускников вузов как необходимый этап проектирования ГОС ВПО нового поколения: метод. пособие. М.: Исслед. центр проблем качества подгот. специалистов, 2006. $71 \mathrm{c.}$

9. Байденко В.И., Дж. ван Зантворт. Новые методы и подходы к организации образовательного процесса (Подход, ориентированный на цели). М.: Исслед. центр проблем качества подгот. специалистов, 2001.79 c.

10. Зимняя И.А. Компетентностный подход. Каково его место в системе современных подходов к проблемам образования? (Теоретико-методологический аспект) // Высшее образование сегодня. 2006. № 8. С. 20-26.

11. Тряпицына А.П., Писарева С.А. Современные методологические подходы к исследованию педагогического образования // Человек и образование. 2014. № 3 (40). С. 4-12.

12. Астафьев Д.А. Компетентностный подход в современной философии образования // Молодой ученый. 2010. № 8-2. С. 145-147.

13. Вербицкий А.А. Компетентностный подход и теория контекстного обучения: мат-лы к четвертому заседанию методологического семинара 16 ноября 2004 г. М.: Исследовательский центр проблем качества подготовки специалистов, 2004. 84 с.

14. Компетентностный подход в педагогическом образовании: коллективная монография / под. ред. проф. В.А. Козырева, проф. Н.Ф. Радионовой и проф. А.П. Тряпицыной. СПб.: Изд-во РГПУ им. А.И. Герцена, 2008. 392 с.

15. Ванчакова Н.П., Худик В.А. Преемственность профессионально-педагогического образования врачей в условиях медицинского вуза [Электронный ресурс] // Клиническая и медицинская психология: исследования, обучение, практика: электрон. науч. журн. 2015. № 3 (9). - http://medpsy.ru/climp/2015_3_9/ article23.php.

16. Головина С.Ю., Новикова Н.В. Проблемы применения работодателями профессиональных стандартов (на примере образовательных организаций высшего образования) // Право и образование. 2017. № 8. C. 4-16.

17. Гуслова О.С. Поэтапное обучение студентов решению учебно-профессиональных задач // Известия Российского государственного педагогического университета им. А.И. Герцена. 2013. № 161. С. 224228.

18. Астанина С.Ю. Концептуальные основы биологической подготовки врачей в дополнительном профессиональном образовании // Современные наукоемкие технологии. 2018. № 9. С. 150-154.

19. Кулюткин Ю.Н., Сухобская Г.С., Петров Я.И. Психологические проблемы непрерывного образования // Теоретические основы непрерывного образования. М.: Педагогика, 1987. С. 161-208.

20. Федеральный закон от 21 ноября 2011 г. N 323-Ф3 «Об основах охраны здоровья граждан в Российской Федерации» [Электронный ресурс] // http://base.garant.ru/12191967. 


\section{TYPES OF EDUCATIONAL AND PROFESSIONAL TASKS USED FOR DOCTORS' TRAINING}

\section{(C) 2018}

Astanina Svetlana Yurievna, candidate of pedagogical sciences, professor of Medical Pedagogy, Philosophy and Foreign Languages Department, head of Scientific, Methodological and Educational Activities Department Russian Medical Academy of Continuing Professional Education (Moscow, Russian Federation)

Abstract. The paper deals with the problem of the fundamental training of doctors on the basis of solving various groups of educational and professional tasks in continuing medical education. Analysis of various scientists' views allowed the authors to determine that the continuity and integrity of education is ensured by continuity in solving educational and professional tasks, formed from professional tasks. Due to the fact that in health care there is a fairly rapid introduction of the basic sciences (molecular biology, biophysics, biochemistry) achievements results into the processes of medical care, the knowledge-intensiveness of labor functions increases, their diversity increases, which leads to an increase in professional tasks. The interrelation of types and classes of educational and professional tasks ensures the continuity of the content of the fundamental training of doctors. Intra-subject relationships are formed between groups of educational and professional tasks (invariant and variable), ensuring the integrity of the content of the biological training of doctors. Division of educational and professional tasks into classes and types allows to systematize the content of fundamental training of doctors in accordance with the actual educational needs of the trained doctors and the requirements of practical public health, which in turn ensures continuity, expressed in the sequence and consistency of the content, forms and methods of the educational process; in the consistency and coherence of training at various stages of medical education.

Keywords: fundamental training of doctors; additional professional education; continuity of medical education; continuity of vocational education; biomedical training; professional tasks; educational and professional tasks; types of educational and professional tasks.

\section{СТАНОВЛЕНИЕ ПРОФЕССИОНАЛЬНОЙ ИДЕНТИЧНОСТИ КАК ФАКТОР ПРОЕКТИРОВАНИЯ КАРЬЕРНОЙ СТРАТЕГИИ СОВРЕМЕННОГО СТУДЕНТА ВУЗА}

(C) 2018

Беркутова Диана Искандеровна, кандидат педагогических наук,

доцент кафедры методик математического и информационно-технологического образования

Громова Екатерина Михайловна, кандидат педагогических наук, доцент кафедры методик математического и информационно-технологического образования

Горшкова Татьяна Анатольевна, кандидат педагогических наук, доцент кафедры методик математического и информационно-технологического образования Ульяновский государственный педагогический университет имени И.Н. Ульянова (2. Ульяновск, Российская Федерачия)

Аннотация. В статье акцентировано внимание исследователей на проблеме становления профессиональной идентичности современной молодежи, которое, по мнению авторов, напрямую связано с проектированием карьерной стратегии. Авторами проанализированы основные теоретические подходы к сущности понятий «профессиональная идентичность», «личная профессиональная перспектива» и «карьерная стратегия». В статье представлены результаты исследования авторским коллективом профессиональных планов современных студентов педвуза в контексте планирования ими профессиональной карьеры. Экспериментальную выборку респондентов составили студенты очной формы обучения факультета физико-математического и технологического образования ФГБОУ ВО «Ульяновский государственный педагогический университет имени И.Н. Ульянова». Диагностирование респондентов проводилось по методике Н.С. Пряжникова «Личная профессиональная перспектива», способствующей стимулированию размышлений молодых людей над сложными многоаспектными мировоззренческими проблемами бытия, выбора профессионального пути, построения успешной карьеры и провоцированию индивидуальных консультаций ценностно-смыслового характера, а также по методике Э. Шейна «Якоря карьеры», которая используется для определения ведущих профессиональных мотивов. Полученные результаты исследования подвергнуты тщательному анализу. В статье приводятся результаты проведенных диагностик, доказывающие, что личная профессиональная перспектива и карьерная стратегия тесно взаимосвязаны. Материалы, которые были получены в ходе представленного исследования, могут служить отправной точкой для дальнейших разработок теоретического и практического характера по проблеме проектирования карьерной стратегии современной молодежи.

Ключевые слова: профессия; профессиональное самоопределение; профессиональные планы; карьерная стратегия; профессиональная идентификация; профессиональная идентичность; ценностные ориентации; информационная культура; студенчество; методика Н.С. Пряжникова «Личная профессиональная перспектива»; методика Э. Шейна «Якоря карьеры». 